\title{
Study of the Effect of Silica Filler Silica 1165 on the Properties of Rubber for Rail Fastening Gaskets
}

\author{
Evgeniy N. Egorova, Nikolay F. Ushmarin ${ }^{b}$, \\ Sergei I. Sandalov ${ }^{b}$, Vladimir S. Grigor'eva, \\ Nikolay I. Kol'tsova and Vasiliy D. Voronchikhin ${ }^{c^{*}}$ \\ ${ }^{a}$ Chuvash State University after named I. N. Ulyanov \\ Cheboksary, Russian Federation \\ ${ }^{b}$ Cheboksary Production Association named after V. I. Chapaev \\ Cheboksary, Russian Federation \\ ${ }^{c}$ Reshetnev Siberian State University of Science and Technology \\ Krasnoyarsk, Russian Federation
}

Received 11.01.2022, received in revised form 21.01.2022, accepted 25.01.2022

\begin{abstract}
The effect of silica filler Silica 1165 instead of kaolin and carbon black N220 on the plastoelastic, rheometric, physical-mechanical, operational and dynamic properties of rubber based on generalpurpose caoutchoucs was investigated in order to develop effective noise and vibration-absorbing rubber gaskets of rail fasteners for railway tracks. It has been established that the developed rubber with a sulfur vulcanizing system based on SKMS-30ARK, SKI-3 и SKD caoutchoucs with Silica 1165 additives has improved plasto-elastic and rheometric indicators, satisfactory physical and mechanical properties, is characterized by an increase in the vibration-absorbing properties of rubber, which is the determining factor for under-rail pads.
\end{abstract}

Keywords: rubber, caoutchoucs, rail fastening gaskets, Silica 1165, kaolin, carbon black N220, plastoelastic, rheometric, physical-mechanical and dynamic properties, tangent of the angle of mechanical losses, modulus of elasticity.

Citation: Egorov, E. N., Ushmarin, N. F., Sandalov, S. I., Grigor'ev, V. S., Kol'tsov, N. I., Voronchikhin V.D. Study of the effect of silica filler Silica 1165 on the properties of rubber for rail fastening gaskets. J. Sib. Fed. Univ. Chem., 2022, 15(1), $110-117$. DOI: $10.17516 / 1998-2836-0276$

(C) Siberian Federal University. All rights reserved

This work is licensed under a Creative Commons Attribution-NonCommercial 4.0 International License (CC BY-NC 4.0).

* Corresponding author E-mail address: vvd-77@mail.ru

ORCID: 0000-0003-1739-3122 (Egorov E.N.); 0000-0003-2967-0297 (Ushmarin N.F.); 0000-0002-7239-4622 (Sandalov S.I.); 0000-0003-3437-9541 (Grigor'ev V.S.); 0000-0003-2264-1370 (Kol'tsov N.I.); 0000-0002-4176-861X (Voronchikhin V.D.) 


\title{
Исследование влияния кремнекислотного наполнителя Silica 1165 на свойства резины для прокладок рельсовых скреплений
}

\author{
Е.Н. Егоров ${ }^{\text {a }, ~ Н . ~ Ф . ~ У ш м а р и н ~}{ }^{\sigma}$, С.И. Сандалов ${ }^{\sigma}$, \\ В. С. Григорьев ${ }^{\text {a }}$ Н. И. Кольцов ${ }^{\text {a }}$ В. Д. Ворончихинв \\ аЧувашский государственный университет им. И. Н. Ульянова \\ Российская Федерачия, Чебоксары \\ ${ }^{б}$ Чебоксарское производственное объединение им. В. И. Чапаева \\ Российская Федерачия, Чебоксары \\ ${ }^{8}$ Сибирский государственный университет науки \\ и технологий им. ак. М. Ф. Решетнева \\ Российская Федераиия, Красноярск
}

\begin{abstract}
Аннотация. Исследовано влияние кремнекислотного наполнителя Silica 1165 взамен каолина и технического углерода N220 на пласто-эластические, реометрические, физико-механические, эксплуатационные и динамические свойства резины на основе каучуков общего назначения с целью разработки эффективных шумо- и вибропоглощающих резиновых прокладок рельсовых скреплений для железнодорожных путей. Установлено, что применение кремнекислотного наполнителя Silica 1165 в составе исследованной резины приводит к повышению ее стойкости к преждевременной вулканизации, удовлетворительным физико-механическим свойствам и увеличению вибропоглощающих свойств, что является определяющим фактором для подрельсовых прокладок.
\end{abstract}

Ключевые слова: резина, каучуки, прокладки рельсовых скреплений, Silica 1165, каолин, технический углерод N220, пласто-эластические, реометрические, физико-механические и динамические свойства, тангенс угла механических потерь, модуль упругости.

Цитирование: Егоров, Е.Н. Исследование влияния кремнекислотного наполнителя Silica 1165 на свойства резины для прокладок рельсовых скреплений / Е.Н. Егоров, Н. Ф. Ушмарин, С. И. Сандалов, В. С. Григорьев, Н.И. Кольцов, В. Д. Ворончихин // Журн. Сиб. федер. ун-та. Химия, 2022, 15(1). С. 110-117. DOI: 10.17516/1998-2836-0276

\section{Введение}

Железнодорожный транспорт - один из экономически эффективных высокоскоростных видов транспорта. Движение поездов вызывает шум и вибрацию, которые оказывают негативное влияние на самочувствие и здоровье людей. Одним из способов их снижения является использование высокоупругих резиновых прокладок для рельсовых креплений, которые должны быть холодо- и термостойкими, обладать стойкостью к истиранию и быть устойчивыми к длительному сроку эксплуатации. Прокладки выполняют функции амортизаторов железнодорожного пути, обеспечивают продольное сопротивление перемещению рельса, компенсируют динамические нагрузки на шпалы и снижают резонансные колебания [1]. 
Для повышения эксплуатационных свойств подрельсовых прокладок необходима разработка рецептур резиновых смесей путем использования специальных добавок. К ним относится транс-полинорборнен (транс-полибицикло[2,2,1]гепт-2-ен) [2, 3]. В работах [4-8] исследована возможность его применения для повышения звуко- и вибропоглощающих свойств резин для резиновых изделий, эксплуатируемых в морской воде [4-6], и для резины марки 81-730 для прокладок рельсовых скреплений $[7,8]$. Однако с увеличением скорости движения поездов и вызванным при этом повышении уровня вибрации и шума возрастают требования по звуко- и вибропоглощающим свойствам к прокладкам рельсовых скреплений, что можно достичь путем дальнейшего совершенствования рецептуры резин за счет новых перспективных добавок. К таким добавкам следует отнести кремнезем, средний размер частиц которого не превышает 0,02 мкм и удельная площадь поверхности составляет 150-175 м²/г [9]. Этот минеральный наполнитель используется для улучшения физико-механических свойств, особенно таких, как условная прочность при растяжении и относительного удлинения при разрыве, сопротивление раздиру и стойкость к истиранию. В связи с этим в данной работе исследовано влияние кремнезема марки Silica 1165 на пласто-эластические, реометрические, физико-механические, эксплуатационные и динамические свойства резины на основе каучуков общего назначения (бутадиен-метилстирольного, изопренового и бутадиенового) с целью разработки эффективных звуко- и вибропоглощающих резиновых прокладок рельсовых скреплений для железнодорожных путей.

\section{Экспериментальная часть}

Основой исследуемой резиновой смеси с серной вулканизующей системой служили синтетические бутадиен-метилстирольный СКМС-30АРК, изопреновый СКИ-3 и бутадиеновый СКД каучуки. Резиновая смесь также включала следующие ингредиенты: ТПНК (смесь трансполинорборнена, капролактама, стеарина и индустриального масла И-12А), серу, сульфенамид Ц, белила цинковые, N, N'-дитиодиморфолин, диафен ФП, ацетонанил Н, канифоль, каолин, технический углерод N220, микросферы HCM-L, гепсол ХКП и воск 3B-П, N-HДФА. В табл. 1 приведены варианты резиновой смеси, в которых проводилась замена каолина и технического N220 на Silica 1165.

Первый вариант резиновой смеси не содержал Silica 1165. Во-втором, третьем и четвертом вариантах Silica 1165 полностью заменила каолин и частично технический углерод N220. В пятом и шестом вариантах каолин и технический углерод N220 были частично заменены

Таблица 1. Варианты резиновой смеси

Table 1. Variants of rubber mixture

\begin{tabular}{|l|c|c|c|c|c|c|}
\hline \multicolumn{2}{|c|}{ Наименование материалов } & \multicolumn{7}{c|}{ Варианты } \\
\cline { 2 - 8 } & 1 & 2 & 3 & 4 & 5 & 6 \\
\hline Каолин, мас. ч. & 20,00 & - & - & - & 10,00 & 20,00 \\
\hline N220, мас. ч. & 60,00 & 70,00 & 60,00 & 50,00 & 40,00 & 30,00 \\
\hline Silica 1165, мас. ч. & - & 10,00 & 20,00 & 30,00 & 30,00 & 30,00 \\
\hline
\end{tabular}


на Silica 1165. Во всех шести вариантах резиновой смеси суммарное содержание каолина, технического углерода N220 и Silica 1165 составляло 80,00 мас.ч. на 100,00 мас. ч. каучуков. Приведенные в табл. 1 варианты резиновой смеси готовились на лабораторных вальцах ЛБ $320160 / 160$ при температуре $70{ }^{\circ} \mathrm{C}$ в течение 30 мин. Пласто-эластические свойства резиновой смеси изучали на вискозиметре Муни MV 3000 Basic фирмы «Mon Tech» при $120{ }^{\circ} \mathrm{C}$ в соответствии с ГОСТ 415-75. Вулканизационные (реометрические) характеристики резиновой смеси исследовали на реометре MDR3000 Basic фирмы «Mon Tech» при $150{ }^{\circ} \mathrm{C}$ в соответствии с ГОСТ 12535-84. Резиновую смесь вулканизовали при температуре $150{ }^{\circ} \mathrm{C}$ в течение 30 мин в вулканизационном прессе типа P-V-100-3RT-2-PCD. Для полученных вулканизатов определяли: упруго-прочностные свойства (ГОСТ 270-75); твердость (ГОСТ 263-75); сопротивление раздиру (ГОСТ 262-79). Динамические свойства (тангенс угла механических потерь и модуль упругости) вулканизатов исследовали на динамическом механическом анализаторе Metravib VHF 104 при частоте 1000 Гц, комнатной температуре и степени деформации 0,01 \% (ГОСТ 23326-78).

\section{Результаты и их обсуждение}

На рис. 1 приведены зависимости вязкости от времени для различных вариантов резиновой смеси при $120^{\circ} \mathrm{C}$, а в табл. 2 - следующие из них значения пласто-эластических показателей резиновой смеси.

Как видно из данных табл. 2, увеличение содержания наполнителя Silica 1165 за счет полной замены каолина и частично технического углерода N220 способствует возрастанию всех пласто-эластических свойств резиновой смеси в вариантах 1-4. В вариантах 4-6 при возрастании содержания каолина за счет уменьшения технического углерода N220 при постоянстве со-

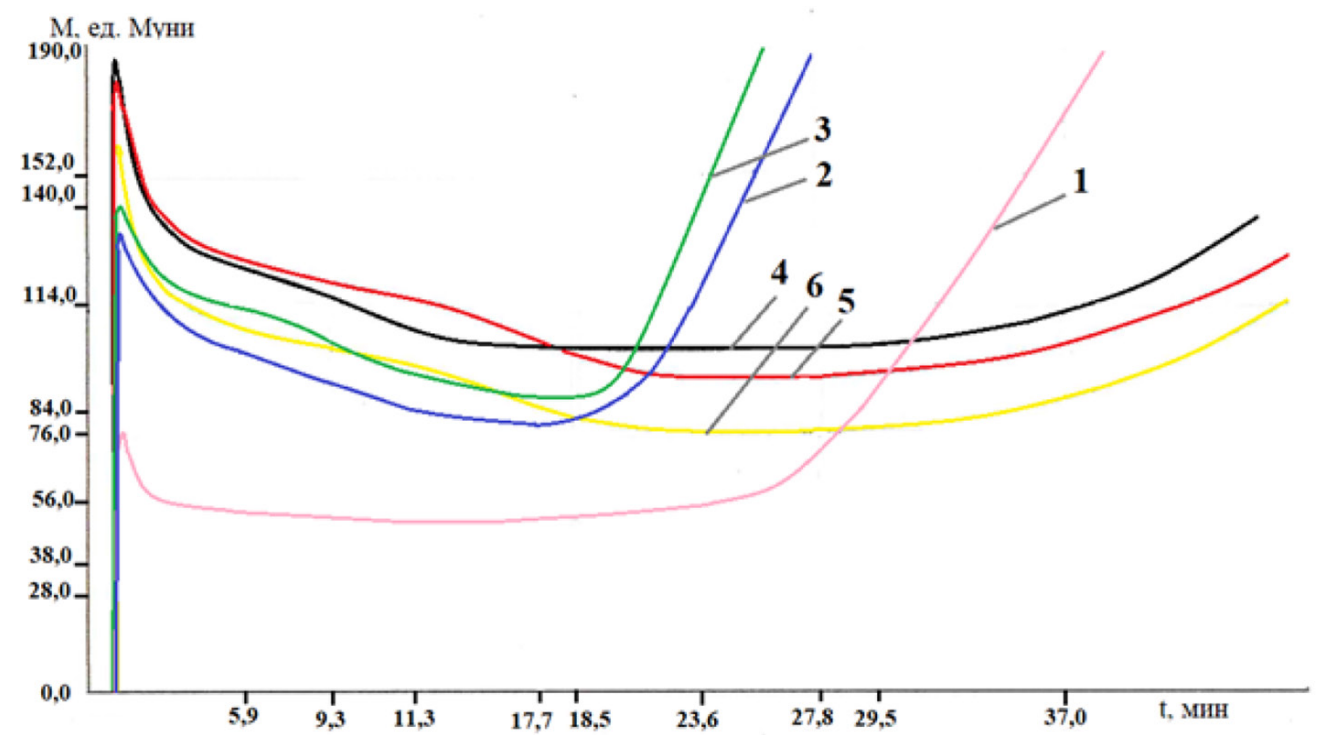

Рис. 1. Изменение вязкости во времени резиновой смеси при $120{ }^{\circ} \mathrm{C}$ (номера кривых соответствуют номерам вариантов)

Fig. 1. Change in viscosity over time of a rubber mixture at $120^{\circ} \mathrm{C}$ (curve numbers correspond to variant numbers) 
Таблица 2. Пласто-эластические показатели резиновой смеси при $120{ }^{\circ} \mathrm{C}$

Table 2. Plasto-elastic indicators of the rubber mixture at $120^{\circ} \mathrm{C}$

\begin{tabular}{|l|c|c|c|c|c|c|}
\hline \multirow{2}{*}{ Показатели } & \multicolumn{7}{|c|}{ Варианты } \\
\cline { 2 - 7 } & 1 & 2 & 3 & 4 & 5 & 6 \\
\hline $\mathrm{M}_{0}$, ед. Муни & 76,20 & 131,16 & 138,73 & 184,96 & 177,92 & 160,12 \\
\hline $\mathrm{t}_{5}$, мин & 23,85 & 19,18 & 26,35 & 33,34 & 33,81 & 33,92 \\
\hline $\mathrm{t}_{35}$, мин & 29,15 & 24,60 & 33,59 & 43,66 & 45,32 & 44,71 \\
\hline
\end{tabular}

Примечание: $\mathrm{M}_{0}$ - начальная вязкость, $\mathrm{t}_{5}$ и $\mathrm{t}_{35}$ - времена до начала подвулканизации при $\mathrm{M}_{0}+5$ и конца подвулканизации при $\mathrm{M}_{0}+35$.

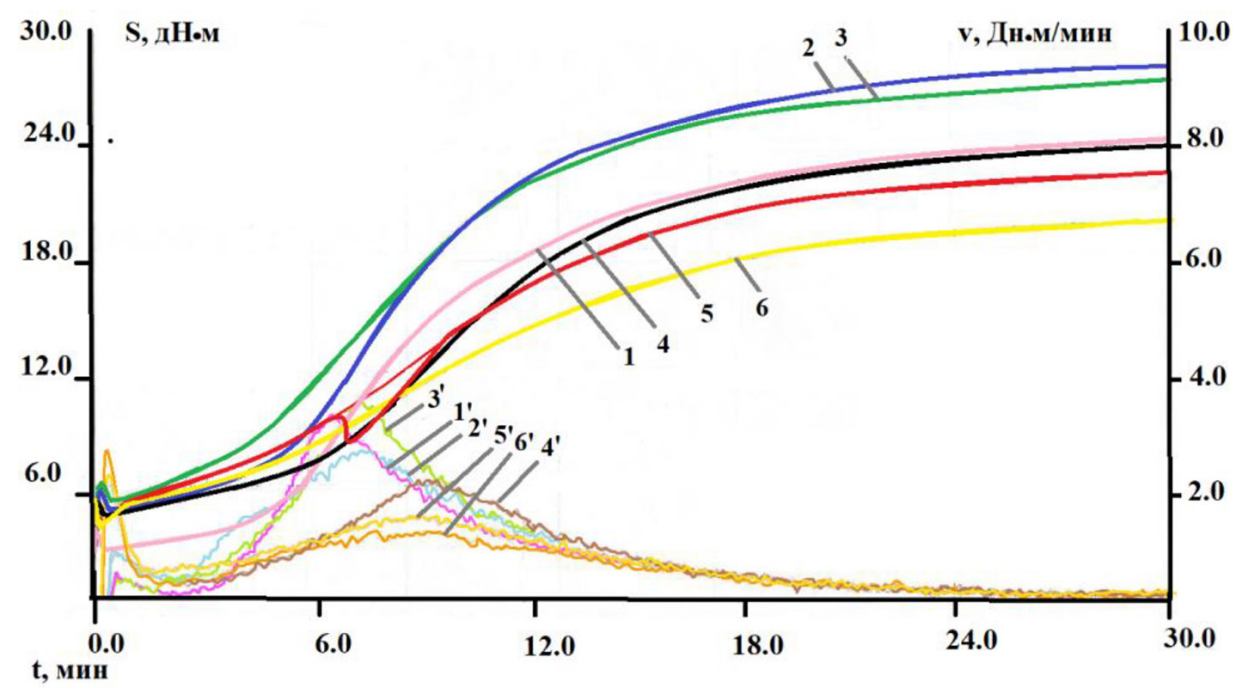

Рис. 2. Вулканизационные кривые резиновой смеси при $150{ }^{\circ} \mathrm{C}$ (номера кривых соответствуют номерам вариантов): 1-6-зависимости крутящего момента от времени; 1'-6'-зависимости скорости вулканизации от времени

Fig. 2. Rheometric curves of a rubber mixture at $150{ }^{\circ} \mathrm{C}$ (curve numbers correspond to variant numbers): $1-6-$ dependences of torque on time; 1'-6' - time dependences of the vulcanization rate

держания кремнекислотного наполнителя наблюдается понижение вязкости и незначительное возрастание времен подвулканизации резиновой смеси.

На рис. 2 приведены вулканизационные кривые для различных вариантов резиновой смеси при $150{ }^{\circ} \mathrm{C}$, на основании которых были определены ее реометрические показатели, представленные в табл. 3 .

Из данных табл. 3 следует, что с увеличением содержания Silica 1165 в вариантах 1-4 наблюдается возрастание максимального и минимального крутящих моментов. В вариантах 4-6 при возрастании содержания каолина, постоянстве содержания Silica 1165 и уменьшении технического углерода N220 происходит уменьшение крутящих моментов и возрастание времен начала и оптимума вулканизации резиновой смеси.

Путем вулканизации различных вариантов резиновой смеси в прессе при $150{ }^{\circ} \mathrm{C}$ в течение 30 мин готовились вулканизаты. Для полученных вулканизатов определялись деформационно- 
Таблица 3. Реометрические показатели резиновой смеси при 150 C

Table 3. Rheometric parameters of the rubber mixture at $150{ }^{\circ} \mathrm{C}$

\begin{tabular}{|l|c|c|c|c|c|c|}
\hline \multirow{2}{*}{ Показатели } & \multicolumn{7}{|c|}{ Варианты } \\
\cline { 2 - 7 } & 1 & 2 & 3 & 4 & 5 & 6 \\
\hline $\mathrm{S}_{\max }$, дН·м & 22,96 & 27,13 & 26,34 & 24,06 & 22,70 & 20,18 \\
\hline $\mathrm{S}_{\min }$, дН·м & 3,44 & 5,42 & 6,17 & 4,86 & 4,85 & 4,43 \\
\hline $\mathrm{t}_{\mathrm{s}}$, мин & 0,05 & 0,06 & 0,06 & 0,05 & 0,07 & 0,08 \\
\hline $\mathrm{t}_{90}$, мин & 14,49 & 13,89 & 13,31 & 13,07 & 18,41 & 19,34 \\
\hline
\end{tabular}

Примечание: $\mathrm{S}_{\max }$ и $\mathrm{S}_{\min }$ - максимальный и минимальный крутящие моменты; $\mathrm{t}_{\mathrm{s}}$ и $\mathrm{t}_{90}$ - времена начала и оптимума вулканизации.

Таблица 4. Физико-механические свойства вулканизатов

Table 4. Physical-mechanical properties of vulcanizates

\begin{tabular}{|l|c|c|c|c|c|c|}
\hline \multirow{2}{*}{ Показатели } & \multicolumn{7}{|c|}{ Варианты } \\
\cline { 2 - 7 } & 1 & 2 & 3 & 4 & 5 & 6 \\
\hline$f_{p}$, МПа & 18,7 & 17,7 & 16,6 & 14,7 & 13,4 & 13,2 \\
\hline$\varepsilon_{p}, \%$ & 320 & 350 & 410 & 460 & 570 & 640 \\
\hline$H$, ед. Шор А & 81 & 82 & 81 & 80 & 79 & 77 \\
\hline$S, \%$ & 24 & 20 & 20 & 16 & 18 & 20 \\
\hline$B$, кН/м & 88 & 85 & 79 & 75 & 76 & 75 \\
\hline$\alpha, \mathrm{M}^{3} /$ ТДж & 61,5 & 57,7 & 58,2 & 63,4 & 65,6 & 67,9 \\
\hline
\end{tabular}

Примечание: $f_{\mathrm{p}}$ - условная прочность при растяжении; $\varepsilon_{\mathrm{p}}$ - относительное удлинение при разрыве; $H$ - твердость по Шору А и ИСО; $S$ - эластичность по отскоку; $B$ - сопротивление раздиру; $\alpha$ - истираемость.

прочностные свойства (условная прочность при растяжении и относительное удлинение при разрыве), а также твердость по А. Шору, эластичность по отскоку и сопротивление раздиру, значения которых приведены в табл. 4.

Из данных табл. 4 следует, что в вариантах 1-4 полная замена каолина и частичная замена технического углерода N220 на Silica 1165 приводит к увеличению относительного удлинения при разрыве и уменьшению условной прочности при растяжении, эластичности по отскоку и сопротивления раздиру при сохранении твердости вулканизатов. Такие же закономерности наблюдаются с возрастанием содержания каолина для вулканизатов вариантов 4-6 для относительного удлинения при разрыве и условной прочности при растяжении с изменением их значений в допустимых пределах. Вулканизаты вариантов 4-6 характеризуются возрастанием эластичности по отскоку, истираемости и сохранением величин сопротивления раздиру.

В дальнейшем проводились исследования изменения физико-механических свойств вулканизатов после выдержки в СЖР-1 при $100{ }^{\circ} \mathrm{C}$ в течение 24 ч. Результаты исследования отражены в табл. 5 .

Из данных табл. 5 следует, что по изменению физико-механических свойств после воздействия жидкости СЖР-1 исследованные варианты вулканизатов равноценны. 
Таблица 5. Изменение физико-механических свойств вулканизатов после выдержки в СЖР-1

Table 5. Changes of the physical-mechanical properties of vulcanizates after aging in SZhR-1

\begin{tabular}{|l|c|c|c|c|c|c|}
\hline \multirow{2}{*}{ Показатели } & \multicolumn{7}{|c|}{ Варианты резиновой смеси } \\
\cline { 2 - 7 } & 1 & 2 & 3 & 4 & 5 & 6 \\
\hline$\Delta \mathrm{f}_{\mathrm{p}}, \%$ & $-11,5$ & $-11,3$ & $-11,0$ & $-10,5$ & $-11,1$ & $-12,0$ \\
\hline$\Delta \varepsilon_{\mathrm{p}}, \%$ & $-21,9$ & $-21,5$ & $-21,3$ & $-21,0$ & $-21,9$ & $-22,4$ \\
\hline$\Delta$ Н, ед. Шор А & -3 & -3 & -2 & -2 & -3 & -3 \\
\hline
\end{tabular}

Примечание: $\Delta f_{\mathrm{p}}$ и $\Delta \varepsilon_{\mathrm{p}}-$ относительное изменение показателя (условной прочности при растяжении и относительного удлинения при разрыве); $\Delta H$ - разность твердостей вулканизатов после и до воздействия СЖР-1.

Таблица 6. Тангенс угла механических потерь и модуль упругости для различных вариантов вулканизатов Table 6. The tangent of the angle of mechanical losses and the modulus of elasticity for different variants of vulcanizates

\begin{tabular}{|l|c|c|c|c|c|c|}
\hline \multirow{2}{*}{ Показатель } & \multicolumn{7}{|c|}{ Варианты } \\
\cline { 2 - 7 } & 1 & 2 & 3 & 4 & 5 & 6 \\
\hline $\operatorname{tg} \delta$ & 0,097 & 0,114 & 0,127 & 0,136 & 0,158 & 0,176 \\
\hline $\mathrm{E} \cdot 10^{-7}$, Па & 10,21 & 14,60 & 14,30 & 13,5 & 12,47 & 11,64 \\
\hline
\end{tabular}

В табл. 6 приведены значения динамических параметров (тангенса угла механических потерь $\operatorname{tg} \delta$ и модуля упругости Е) вулканизатов различных вариантов резиновой смеси при резонансной частоте 1000 Гц.

Известно, что тангенс угла механических потерь и модуль упругости характеризуют плотность вулканизационной сетки и способность материала сопротивляться растяжению и сжатию при упругой деформации. Из данных табл. 6 следует, что использование Silica 1165 в вариантах 1-4 способствует возрастанию тангенса угла механических потерь и модуля упругости. Для вулканизатов вариантов 4-6, содержащих Silica 1165, при возрастании содержания каолина увеличивается тангенс угла механических потерь и уменьшается модуль упругости. Таким образом, из исследованных вариантов наиболее предпочтительным является вариант 6 резины, характеризующийся улучшенными динамическими свойствами и удовлетворительными физико-механическими показателями.

\section{Выводы}

В ходе проведенных исследований изучено влияние кремнекислотного наполнителя Silica 1165 на свойства резины на основе комбинации каучуков общего назначения. Показано, что применение кремнекислотного наполнителя Silica 1165 в составе исследованной резины приводит к повышению ее стойкости к преждевременной вулканизации, изменяет физико-механические свойства вулканизатов в допустимых пределах и повышает их вибропоглощающие свойства, что является определяющим фактором для подрельсовых прокладок. 


\section{Конфликт интересов}

Авторы заявляют об отсутствии конфликта интересов, требующего раскрытия в данной статье.

\section{Список литературы / References}

1. Буторина М.В., Иванов П. В., Петряев А. В. Снижение виброакустического воздействия высокоскоростных поездов. Путь и путевое хозяйство 2018. № 7. С. 15-19. [Butorina M. V., Ivanov P. V., Petryaev A. V. Reduction of vibroacoustic impact high speed trains. Way and track facilities 2018 (7), P. 15-19. (In Russ.)].

2. Çakmak U.D., Hiptmair F., Major Z. Applicability of elastomer time-dependent behavior in dynamic mechanical damping systems. Mechanics of Time-Depend Materials 2014. Vol. 18(1), P. 139151.

3. Xu J., Li A., Wang H., Shen Y. Dynamic mechanical analysis of Norsorex/acrylonitrile butadiene rubber blends and their application in vibration control of steel frames. Advances in Mechanical Engineering 2016. Vol. 8(8), P. 1-16.

4. Патент 2690807 РФ. Михайлов Ю. М., Резников М.С., Мингазов А.Ш., Ушмарин Н.Ф., Сандалов С.И. Композиционная резиновая смесь для акустических покрытий. Опубл. 05.06.2019. [Patent 2690807 RU. Mikhajlov Yu. M., Reznikov M. S., Mingazov A. S., Ushmarin N. F., Sandalov S. I. Composite rubber mixture for acoustic coatings. Publ. Date 05.06.2019 (In Russ.)].

5. Патент 2675557 РФ. Михайлов Ю.М., Мингазов А.Ш., Резников М.С., Ушмарин Н.Ф., Чумаков К.И., Старухин Л.П. Резиновая смесь для изготовления шумопоглощающих покрытий. Опубл. 19.12.2018. [Patent 2675557 RU. Mikhajlov Yu. M., Mingazov A.S., Reznikov M.S., Ushmarin N.F., Chumakov K.I., Starukhin L.P. Rubber mixture for manufacture of noise absorbing coatings. Publ. Date 19.12.2018 (In Russ.)].

6. Егоров Е.Н., Ушмарин Н.Ф., Сандалов С.И., Кольцов Н.И., Ворончихин В. Д. Исследование динамических свойств стойкой к морской воде резины. Журнал Сибирского федерального университета. Химия 2021. Т. 14(1). C. 38-44. Egorov E.N., Ushmarin N. F., Sandalov S.I., Kol'tsov N.I., Voronchikhin V.D. Investigation of the dynamic properties of seawater-resistant rubber, J. Sib. Fed. Univ. Chem., 2021, 14(1), 38-44. DOI: 10.17516/1998-2836-0214

7. Патент 2739188 РФ. Ушмарин Н.Ф., Егоров Е.Н., Сандалов С.И., Кольцов Н. И. Резиновая смесь. Опубл. 21.12.2020. [Patent 2739188 RU. Ushmarin N.F., Egorov E. N., Sandalov S.I., Kol'tsov N. I. Rubber mixture. Publ. Date 21.12.2020 (In Russ.)].

8. Егоров Е.Н., Ушмарин Н.Ф., Сандалов С.И., Кольцов Н.И. Разработка и исследование резиновой смеси для прокладок рельсовых скреплений. Российский химический журнал (Журнал Российского химического общества имени Д.И. Менделеева) 2021. Т. 65(1). С. 5661. [Egorov E. N., Ushmarin N. F., Sandalov S. I., Koltsov N. I. Development and research rubber compound for rail fasteners. Russian Chemical Journal (Zhurnal of the Russian Chemical Society named after D. I. Mendeleev) 2021. V. 65(1). pp. 56-61. (In Russ.)].

9. Сырье и материалы для резиновой промышленности: Тексты лекций / Н. А. Охотина; Казан. гос. технол. ун-т. Казань, 2005. 116 с. [Raw materials for the rubber industry: Lecture texts, N. A. Okhotina; Kazan. State Technol. Un. Kazan, 2005. 116 p. (In Russ.)]. 